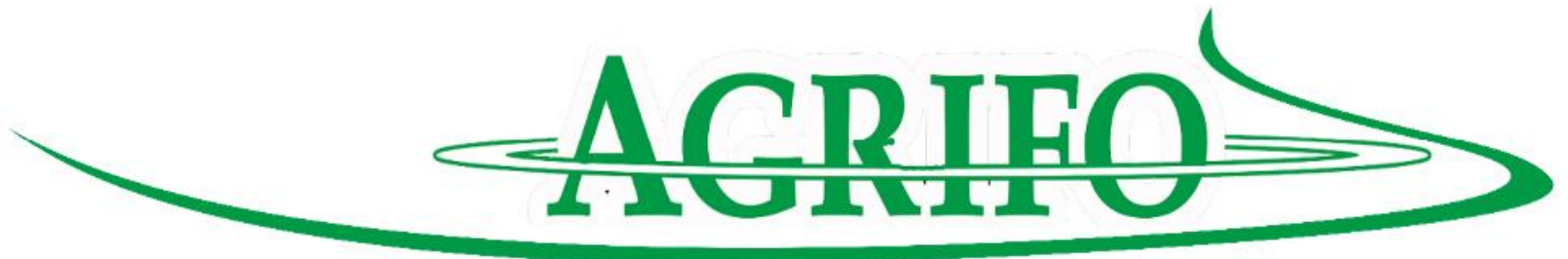

\title{
FAKTOR-FAKTOR YANG MEMPENGARUHI PRODUKSI GARAM RAKYAT DI KECAMATAN SEUNUDDON KABUPATEN ACEH UTARA
}

Ade Mauliza, Suryadi dan Murdani Staff Pengajar Program Studi Agribisnis Fakultas Pertanian

\begin{abstract}
ABSTRAK
Penelitian ini bertujuan untuk mengetahui faktor-faktor yang mempengaruhi produksi garam rakyat di Kecamatan Seunuddon Kabupaten Aceh Utara. Metode penelitian ini menggunakan pendekatan kuantitatif. Metode analisis data menggunakan fungsi produksi Cobb-Douglass.

Hasil penelitian menunjukkan bahwa variabel luas lahan, bibit garam, tenaga kerja dan kayu bakar secara serempak mempunyai pengaruh yang sangat signifikan terhadap produksi garam. Hal ini ditunjukkan oleh nilai probabilitas $\mathrm{F}$ lebih kecil dari alpha $(0,000<0,01)$. Secara parsial faktor-faktor yang mempengaruhi produksi garam rakyat di Kecamatan Seunuddon Kabupaten Aceh Utara adalah variabel bibit dan kayu bakar, sedangkan yang tidak berpengaruh nyata terhadap produksi garam di Kecamatan Seunuddon Kabupaten Aceh Utara adalah variabel luas lahan dan tenaga kerja.
\end{abstract}

Kata Kunci : Faktor produksi, Garam Rakyat

\section{PENDAHULUAN}

Daerah penghasil garam di Provinsi Aceh yaitu terdiri dari Aceh Besar, Pidie, Pidie Jaya, Aceh Utara, Aceh Timur, Aceh Barat Daya, Aceh Selatan, Aceh Tamiang dan Bireuen. Kabupaten Aceh Utara Provinsi Aceh merupakan wilayah agraris dan wilayah/kawasan pesisir atau pantai yang masyarakatnya sebagian besar bermata pencaharian sebagai petani, nelayan dan petani garam (Salim, 2010). Kabupaten Aceh Utara merupakan daerah yang cukup potensial untuk perkembangan usaha pembuatan garam yang dapat menciptakan lapangan kerja bagi masyarakat yang tinggal di daerah ini. Daerah-daerah penghasil garam di Aceh Utara yaitu terdiri dari Kecamatan Dewantara, Syamtalira Bayu, Lapang dan Kecamatan Seunuddon (Rochwulaningsih, 2013).

Kabupaten Aceh Utara merupakan salah satu kabupaten yang terletak tidak jauh dari selat Malaka sehingga keadaan tanah di sekitar 
lancang sira (Pondok Garam) banyak mengandung garam. Hal inilah yang membuat masyarakat pada beberapa kecamatan di Kabupaten Aceh Utara banyak yang bekerja sebagai petani garam. Mereka bekerja secara individual pada lancang sira
(Pondok Garam) milik mereka dan hanya menghasilkan garam tradisional. Usaha sentra pembuatan garam di Kecamatan Seunuddon terdiri dari dua (2) desa yaitu Teupin Kuyun dan Ulee Rubek.

Tabel 1. Produksi garam menurut Kecamatan di Kabupaten Aceh Utara 2014

\begin{tabular}{llrr}
\hline No & \multicolumn{1}{c}{ Kecamatan } & $\begin{array}{c}\text { Luas lahan } \\
\text { (Ha) }\end{array}$ & \multicolumn{2}{c}{$\begin{array}{c}\text { Produksi } \\
\text { (Ton) }\end{array}$} \\
\hline 1 & Dewantara & 0.16 & 420.981 \\
\hline 2 & Syamtalira Bayu & 0.08 & 340.180 \\
\hline 3 & Lapang & 0.41 & 320.645 \\
\hline 4 & Seunuddon & 0.28 & 835.342 \\
\hline & Jumlah & $\mathbf{0 . 9 3}$ & $\mathbf{1 . 9 1 7 . 1 4 8}$
\end{tabular}

Sumber : Dinas Kelautan dan Perikanan Aceh Utara, 2015

Proses produksi garam di

Kecamatan Seunuddon pada umumnya sama dan masih sangat tradisional, yaitu tanah digaruk dengan mengunakan cangkul garpu (Creuh), kemudian dijemur pada terik matahari, selanjutnya tanah ditumpuk menjadi dua tumpukkan yang dialasi dengan pelepah kelapa dan sebelah menyebelah diantara kolam kecil yang telah dibuat terlebih dahulu. Kemudian tumpukkan tanah tersebut satu persatu disiram air laut, sehingga air tirisan mengalir ke dalam kolam kecil. Air hasil tirisan selanjutnya diangkat untuk disimpan di dalam sebuah bak yang terbuat dari kayu dan dilapisi oleh terpal plastik hitam. Kemudian air tersebut diambil sebahagian dan dimasak dengan mengunakan kayu bakar sampai kering sehingga terlihat butiranbutiran warna putih yang berbentuk kristal yang disebut dengan garam. tujuan penelitian ini adalah untuk mengetahui faktor-faktor yang mempengaruhi produksi garam di Kecamatan Seunuddon Kabupaten Aceh Utara.

\section{METODE PENELITIAN}

Penelitian ini dilakukan di dua Desa di Kecamatan Seunuddon yaitu 
Desa Ulee Rubek dan Teupin Kuyun. Pemilihan lokasi dilakukan secara sengaja dengan pertimbangan Desa
Pengambilan sampel dilakukan dengan menggunakan teknik simple random sampling yaitu sebesar $40 \%$ dari jumlah populasi dilokasi penelitian yaitu 36 orang yang dijadikan sebagai sampel penelitian. Adapun perincian jumlah petani garam di Kecamatan Seunuddon Kabupaten Aceh Utara adalah sebagai berikut :

tenaga kerja dan kayu bakar terhadap produksi garam rakyat di Kecamatan Seunuddon Kabupaten Aceh Utara.

Tabel 2. Distribusi wilayah Populasi dan Sampel Petani Garam di Kecamatan Seunuddon Kabupaten Aceh Utara

\begin{tabular}{llcc}
\hline No & Desa & $\begin{array}{c}\text { Populasi } \\
\text { (jiwa) }\end{array}$ & $\begin{array}{c}\text { Sampel } \\
\text { (jiwa) }\end{array}$ \\
\hline 1 & Teupin Kuyun & 52 & 21 \\
\hline 2 & Ulee Rubek & 39 & 15 \\
\hline Jumlah & $\mathbf{9 1}$ & $\mathbf{3 6}$ \\
\hline
\end{tabular}

Sumber : Dinas Kelautan dan Perikanan Aceh Utara, Dalam angka tahun 2014

Untuk mempermudahkan bi : Parameter estimasi

perhitungan dari fungsi tersebut

kemudian ditransformasikan dalam

$\mathrm{X}_{1} \quad$ : Luas lahan (Ha)

bentuk logaritma linier, sehingga

$\mathrm{X}_{2} \quad$ : Bibit garam $(\mathrm{Kg})$

persamaan matematisnya menjadi

$\mathrm{X}_{3} \quad$ : Tenaga kerja $(\mathrm{HOK} / \mathrm{Ha})$

(Situmorang, 2007)

$\operatorname{Ln} Y=a+b_{1} \operatorname{Ln} X_{1}+b_{2} \operatorname{Ln} X_{2}+b_{3}$

$\operatorname{Ln} X_{3}+b_{4} \operatorname{Ln} X_{4}+e$

$\mathrm{X}_{4} \quad$ : Kayu Bakar (Kubit)

e : error term

Keterangan:

\section{Pengujian Hipotesis}

Y : Tingkat produksi garam

Uji F, digunakan untuk mengetahui bentuk hubungan secara

a : Konstanta 
serempak antara variabel bebas $\mathrm{X}$ terhadap variabel terikat $(\mathrm{Y})$.

$$
F_{\text {nitung }} \frac{R^{2} / K}{\left(I-R^{2}\right) /(n-k-1)}
$$

Keterangan :

$\mathrm{R}^{2}=$ Koefisien determinasi

$\mathrm{K}=$ Variabel peubah bebas

$\mathrm{n}$ = Jumlah sampel

Dengan ketentuan:

- $\mathrm{F}_{\text {hitung }}>\mathrm{F}$ tabel, pada taraf nyata 0,05 maka terima $\mathrm{H}_{\mathrm{a}}$ dan tolak $\mathrm{H}_{\mathrm{o}}$

- $F_{\text {hitung }}<F_{\text {tabel }}$, pada taraf nyata 0,05 maka terima $\mathrm{H}_{\mathrm{o}}$ dan tolak $\mathrm{H}_{\mathrm{a}}$

Uji t, digunakan untuk mengetahui pengaruh secara parsial dari variabel bebas $\mathrm{X}$ terhadap variabel terikat $(\mathrm{Y})$

$$
\mathrm{t}_{\text {hitung }}=\underline{\mathrm{bi}}
$$

Sbi

Keterangan :

$\mathrm{bi} \quad=$ Koefisien regresi

$\mathrm{Sbi}=$ Standar error dari koefisien regresi
Dengan ketentuan:

- $\quad t_{\text {hitung }}>t_{\text {tabel, }}$, pada taraf nyata 0,05 maka terima $\mathrm{H}_{\mathrm{a}}$ dan tolak $\mathrm{H}_{\mathrm{o}}$

- $\quad t_{\text {hitung }}<t_{\text {tabel, }}$, pada taraf nyata 0,05 maka terima $\mathrm{H}_{\mathrm{o}}$ dan tolak $\mathrm{H}_{\mathrm{a}}$

Untuk hipotesis diformulasikan sebagai berikut:

- Ho : bi $=0$, artinya luas lahan, bibit garam, tenaga kerja dan kayu bakar berpengaruh nyata terhadap produksi garam.

- Ha : bi $\neq 0$, artinya luas lahan, bibit garam, tenaga kerja dan kayu bakar tidak berpengaruh nyata terhadap produksi garam.

HASIL DAN PEMBAHASAN

Analisis Faktor - faktor Yang Mempengaruhi Produksi Garam Rakyat

Faktor - faktor yang mempengaruhi produksi garam rakyat di Kecamatan Seunuddon Kabupaten Aceh Utara terdiri dari luas lahan, bibit, tenaga kerja dan kayu bakar.

\section{Luas Lahan}

Salah satu faktor yang mempengaruhi tingkat produksi garam adalah luas lahan. Petani 
garam di daerah penelitian, umumnya memproduksi garam pada lahan milik sendiri. Luas lahan yang digunakan

\section{6}

tiap petani untuk usahatani garam di lokasi penelitian cukup beragam yaitu dari 0,0225 Ha hingga 0,05 $\mathrm{Ha}$ dan rata-rata luas lahan di daerah penelitian yaitu $0,038583333 \mathrm{Ha}$

\section{Bibit}

Petani garam di daerah penelitian memproduksi garam dengan menggunakan garam pancing atau bibit garam. Bibit garam di beli oleh petani dengan harga $\mathrm{Rp}$ $60.000 / \mathrm{sak}$ atau $50 \mathrm{~kg}$. dalam satu kali pemasakan garam biasanya petani menggunakan $10 \mathrm{~kg}$ bibit untuk satu kali proses produksi yang dimasak menggunakan air laut. Dalam satu bulan rata-rata bibit garam yang digunakan oleh petani garam di tempat penelitian adalah $318,34 \mathrm{~kg}$.

\section{Tenaga kerja}

Jumlah tenaga kerja yang diperkirakan dalam usahatani garam tidak banyak, paling sedikit satu orang dan paling banyak dua orang. Dari hasil penelitian dapat disimpulkan bahwa jumlah pekerja dalam usaha garam rakyat dalam sehari yaitu paling banyak 2 orang dan paling sedikit 1 orang. Para pekerja ini berasal dari keluarga sendiri Biasanya istri, suami atau juga anak ikut bekerja membantu pembuatan garam.

\section{Kayu Bakar}

Kayu bakar merupakan bahan yang digunakan untuk pembakaran dalam memproduksi garam. Kayu bakar yang digunakan oleh petani garam dalam sehari yaitu sebanyak 0,24 kubik yang digunakan untuk bahan pembakaran dalam proses produksi garam. Dalam satu bulan rata-rata kayu bakar yang digunakan yaitu sebanyak 7,25 kubik

Hasil Analisis Faktor-Faktor Yang Mempengaruhi Produksi

\section{Uji Asumsi Klasik}

1. Uji Normalitas

Untuk mengetahui asumsi normalitas dapat dilihat pada kurva Normal P-P Plot Of Regression Standarlized Residual. Berdasarkan hasil output data pada lampiran 4 dilihat bahwa data menyebar di sekitar diagram dan mengikuti model regresi sehingga dapat disimpulkan 
bahwa data yang diolah merupakan data yang berdistribusi normal sehingga uji normalitas terpenuhi

\section{Uji Multikonieritas}

Berdasarkan tabel coefficients pada lampiran 3 dapat disimpulkan bahwa masing-masing variabel independen memiliki nilai tolerance > 0,10 begitu juga dengan hasil perhitungan yang dimiliki oleh nilai VIF menunjukkan nilai VIF $<10$ jadi dalam model ini tidak terjadi multikolinieritas antara variabel independen

\section{Uji Heteroskedastitas}

Pengujian heteroskedastisitas digunakan untuk melihat apakah variabel pengganggu mempunyai varian yang sama atau tidak. Pengujian gejala heteroskedastisitas dalam persamaan regresi linier berganda dapat diketahui dengan metode Scatterplot. Jika terdapat pola tertentu, seperti titik-titik yang ada membentuk pola tertentu yang teratur (bergelombang, melebar kemudian menyempit), maka mengidentifikasikan telah terjadi heteroskedastisitas. Sebaliknya, jika tidak terdapat pola yang jelas, serta titik-titik menyebar di atas dan dibawah angka 0 pada sumbu $\mathrm{Y}$, maka tidak terjadi heteroskedastisitas, sehingga model regresi tersebut layak digunakan. Dari hasil analisis didapatkan bahwa tidak terjadi heteroskidastitas pada penelitian ini dikarenakan bentuk Scatterplot yang tidak beraturan.

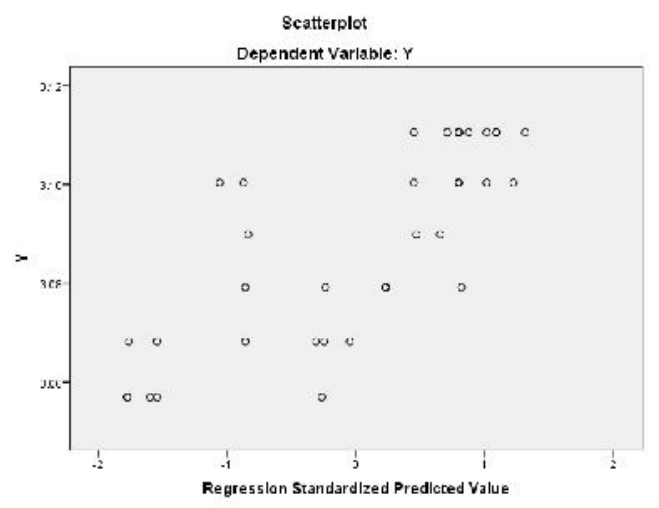

\section{Uji Statistik}

Untuk mengetahui pengaruh faktorfaktor tersebut terhadap produksi maka dilakukan analisis fungsi CobbDoglass. 
Tabel. 5. Hasil Regresi Faktor-faktor yang Mempengaruhi Produksi Garam

\begin{tabular}{|c|c|c|c|c|c|c|}
\hline \multirow{2}{*}{ Model } & \multicolumn{2}{|c|}{$\begin{array}{l}\text { Unstandardizer } \\
\text { coefficients }\end{array}$} & \multirow{2}{*}{$\begin{array}{l}\text { Standardized } \\
\text { coefficients }\end{array}$} & \multirow[t]{2}{*}{$\mathbf{T}$} & \multirow[t]{2}{*}{ Sig } & \multirow{2}{*}{$\begin{array}{l}\text { Collinerarity } \\
\text { Statistics } \\
\text { VIF }\end{array}$} \\
\hline & B & Std.Error & & & & \\
\hline (Constant) & 2.945 & 0.286 & & 10.280 & 0.000 & \\
\hline X1 L. Lahan & -0.003 & 0.016 & -0.025 & -0.204 & 0.840 & 1.171 \\
\hline X2 Bibit & 0.232 & 0.042 & 0.634 & 5.476 & 0.000 & 1.058 \\
\hline X3 T. Kerja & 0.077 & 0.087 & 0.101 & 0.890 & 0.380 & 1.025 \\
\hline X4 K. Bakar & -0.662 & 0.240 & -0.336 & -2.759 & 0.010 & 1.170 \\
\hline $\begin{array}{l}R=0.779 \\
R^{2}=0.607\end{array}$ & $\begin{array}{l}F_{\text {hitung }}= \\
F_{\text {Sig }}=\end{array}$ & $\begin{array}{l}1.954 \\
.000\end{array}$ & & & & \\
\hline
\end{tabular}

Sumber : Data primer (diolah)

Uji F

Berdasarkan Tabel 5
diperoleh faktor-faktor yang
mempengaruhi produksi garam yaitu sebagai berikut:

$\operatorname{LnY}=\operatorname{Ln} 2.945-0.003 \operatorname{LnX}_{1}+0.232$

$$
\begin{aligned}
& \operatorname{LnX}_{2}+0.077 \operatorname{LnX}_{3}-0.662 \\
& \operatorname{LnX}_{4}+\mathrm{E}
\end{aligned}
$$

Nilai koefesien determinasi $\left(\mathrm{R}^{2}\right)$ sebesar 0,607 ini menunjukkan bahwa variasi luas lahan, bibit garam, tenaga kerja dan kayu bakar mampu menjelaskan variasi produksi garam sebesar $60,7 \%$ dan sisanya $39,3 \%$ dijelaskan oleh variabel lain di luar model.

Uji $F$ adalah uji serempak untuk melihat pengaruh semua variabel secara bersama terhadap variabel terikat. Perbandingan nilai signifikan $F$ dengan alpha menunjukkan bahwa nilai signifikan F lebih kecil dari alpha $(0,000<0,01)$, berarti secara serempak semua variabel bebas luas lahan, bibit garam, tenaga kerja dan kayu bakar memiliki pengaruh yang sangat nyata terhadap produksi garam.

Uji t secara parsial terlihat bahwa variabel luas lahan dan tenaga kerja tidak berpengaruh nyata terhadap produksi garam, sedangkan variabel bibit dan kayu bakar berpengaruh nyata terhadap produksi garam.

Variabel luas lahan (X1) tidak berpengaruh nyata terhadap produksi garam (Y) yang ditunjukkan oleh nilai signifikan lebih besar dari alpha yaitu $0,840>0,05$. Tidak signifikannya 
variabel luas lahan terhadap produksi garam rakyat dikarenakan dalam proses produksi para petani garam lebih banyak menggunakan bibit garam.

Variabel bibit garam (X2) berpengaruh sangat nyata terhadap produksi garam (Y) yang ditunjukkan oleh nilai signifikan lebih kecil dari alpha yaitu $0,000<0,01$. Koefesien regresi sebesar 0,232, dapat diartikan bahwa setiap penambahan bibit garam sebesar $10 \%$ maka akan meningkatkan produksi sebesar 2,32 $\%$. Hal ini berarti bahwa apabila bibit garam yang digunakan oleh petani semakin banyak maka akan menambah produksi garam. Rata-rata penggunaan bibit garam di tempat penelitian yaitu sebanyak 318,34 $\mathrm{kg} / \mathrm{bulan}$.

Variabel tenaga kerja (X3) tidak berpengaruh nyata terhadap produksi garam (Y) yang ditunjukkan oleh nilai signifikan $\mathrm{t}$ lebih besar dari alpha yaitu $0.380>$ 0,05 . Tidak berpengaruhnya variabel tenaga kerja terhadap produksi garam, dikarenakan dalam proses produksi garam tidak banyak memerlukan tenaga kerja. Pada proses produksi garam tenaga kerja dibutuhkan pada saat pengangkutan air laut dari tambak atau tempat penampungan untuk dimasak dan proses pemasakan. berpengaruh sangat nyata terhadap produksi garam (Y) karena nilai signifikan t lebih kecil dari alpha yaitu $0,010<0,05$. Berpengaruhnya kayu bakar pada produksi garam dikarena dalam proses produksi garam banyak memakai kayu bakar. Koefesien regresi sebesar -0,662 dapat diartikan bahwa setiap penambahan kayu bakar sebanyak 10 $\%$ maka akan menurunkan produksi garam sebanyak 6,62\%. 1 truk kayu bakar bisa memproduksi garam selama 25 hari. Kayu bakar yang selama ini dipakai kualitasnya kurang bagus sehingga jumlah kayu yang digunakan semakin meningkat, tapi di sisi lain jumlah produksi tetap sama, sehingga dalam 1 truk kayu bakar tidak mencukupi lagi untuk 25 hari. Dengan menggunakan kayu bakar yang lebih banyak maka proses produksi garam bisa lebih cepat selesai, akan tetapi petani garam tetap memproduksi garam dalam jumlah 
yang sama walaupun dalam proses produksi lebih hemat waktu namun petani garam hanya memproduksi 40 garam 2 kali dalam satu hari. Rata-
3. Faktor-faktor yang mempengaruhi produksi garam di Kecamatan Seunuddon rata penggunaan kayu bakar dilokasi penelitian yaitu sebanyak 7,25 kubik/bulan.

\section{KESIMPULAN}

1. Uji serempak melihat pengaruh semua variabel secara bersamasama terhadap variabel terikat. Perbandingan nilai signifikan $\mathrm{F}$ dengan alpha menunjukkan bahwa nilai signifikan $\mathrm{F}$ lebih kecil dari alpha $(0,000<0,01)$, berarti secara serempak semua variabel bebas luas lahan, bibit garam, tenaga kerja dan kayu bakar memiliki pengaruh yang sangat nyata terhadap produksi garam.

2. Koefesien determinasi $\left(\left(\mathrm{R}^{2}\right)\right.$ sebesar 0,607 ini menunjukkan bahwa variasi luas lahan, bibit garam, tenaga kerja dan kayu bakar mampu menjelaskan variasi produksi garam sebesar $60,7 \%$ dan sisanya 39,3\% dijelaskan oleh variabel lain di luar model.
Kabupaten Aceh Utara adalah bibit garam (X2) dan kayu bakar (X4) yang ditunjukkan oleh nilai signifikan t lebih kecil dari alpha $<0,05$.

\section{SARAN}

Dalam rangka membantu meningkatkan produksi garam maka, disarankan kepada pemerintah agar dapat memberikan bantuan bibit garam kepada para petani garam dan kepada para penyuluh pertanian agar menghimbau masyarakat untuk memanfaatkan garam tradisional sebagai salah satu dari Sembilan kebutuhan pokok sehari-hari. Kepada para petani garam untuk membuat kemasan pada produk garam agar konsumen lebih mengenal produksi garam Seunuddon.

\section{DAFTAR PUSTAKA}

Dinas Kelautan dan Perikanan Aceh Utara. (2015). Produksi garam menurut Kecamatan di Kabupaten Aceh Utara 2014.

Rochwulaningsih, Y. (2013). Kajian Sosiokultural Usaha Garam 
Rakyat di Aceh. HUMANIKA, 18(2).

Salim, M. (2010). Dinamika Kebijakan Kelautan dan Perikanan Kabupaten Rembang Pada Masa Reformasi dan Otonomi Daerah Tahun 1998-2008. Universitas Diponegoro.

Situmorang, J. (2007). Analisis Produktivitas Dengan
Menggunakan Fungsi

Produksi Cobb-Douglas Dalam Menentukan Return To Scale Pada PT. Perkebunan Nusantara IV Sawit Langkat. Analisis Produktivitas Dengan Menggunakan Fungsi Produksi Cobb-Douglas Dalam Menentukan Return To Scale Pada PT. Perkebunan Nusantara IV Sawit Langkat. 